\title{
CARACTERÍSTICAS DAS DIMENSÕES DAS FIBRAS E ANÁLISE DO ÂNGULO MICROFIBRILAR DE Toona ciliata CULTIVADA EM DIFERENTES LOCALIDADES
}

\author{
Alessandra de Oliveira Ribeiro ${ }^{1}$, Fábio Akira Mori ${ }^{2}$, Lourival Marin Mendes ${ }^{3}$ \\ ${ }^{1}$ Bióloga, Mestranda em Ciência e Tecnologia da Madeira, UFLA, Lavras, MG, Brasil - alebioribeiro@ gmail.com \\ ${ }^{2}$ Eng. Florestal, Dr., Depto. de Ciências Florestais, UFLA, Lavras, MG, Brasil - fabio.mori@pq.cnpq.br \\ ${ }^{3}$ Eng. Florestal, Dr., Depto. de Ciências Florestais, UFLA, Lavras, MG, Brasil - lourival@ufla.br
}

Recebido para publicação: 02/03/2009 - Aceito para publicação: 11/05/2010

\begin{abstract}
Resumo
O presente trabalho teve como objetivos determinar as dimensões das fibras e avaliar o ângulo microfibrilar da madeira de cedro australiano aos 4 anos de idade, no sentido axial base-topo, proveniente dos municípios de Cana Verde, Campo Belo e Santo Antônio do Amparo, localizados na região do sul de Minas Gerais. A partir da altura comercial de cada árvore, foi retirada uma tábua com $5 \mathrm{~m}$ de comprimento, da qual foram retiradas amostras em três posições: base, 50 e $100 \%$. Os elementos anatômicos foram mensurados por meio de análise de imagens. Conclui-se que a correlação do AMF com a parede e lume das fibras foi positiva, sendo negativa apenas a interação AMF com o comprimento das fibras em Cana Verde. Em Santo Antônio do Amparo a correlação foi baixa. Não houve um padrão definido da variação no ângulo microfibrilar com as dimensões das fibras no sentido axial por município. As dimensões das fibras apresentaram características semelhantes às do eucalipto. Estudos complementares são necessários para um melhor direcionamento do uso da espécie.

Palavras-chave: Dimensões das fibras; ângulo microfibrilar; Toona ciliata.
\end{abstract}

\begin{abstract}
Fibers dimensions characteristics and microfibril angle analisys of Toona ciliata cultivated at different places. The objective of this work was to determine the fibers dimensions and to evaluate the microfibril angle of the wood of Australian cedar with 4 years of age, in the axial direction base-top, proceeding from the municipal districts of the Cana Verde, Campo Belo and Santo Antonio do Amparo, located in the region of the South of Minas Gerais. From the commercial height of each tree, a board with $5 \mathrm{~m}$ of length was removed, from this board it was taken samples in three positions: base, 50 and $100 \%$. The anatomical elements were measured through image analysis. Concluded that: the correlation of the AMF with the wall and fire of fibers dimensions was positive and negative only interaction AMF with the fiber length in municipal districts of Cana Verde and in Santo Antonio do Amparo, was low. Top for municipal district did not have a definite standard of variation in the microfibril angle with the fibers dimensions in the axial direction from municipal district. The fibers dimensions presented similar characteristics of the eucalipto. Complementary studies are necessary for one better aiming of the use of the species.
\end{abstract}

Keywords: Fiber dimensions; microfibril angle; Toona ciliata.

\section{INTRODUÇÃO}

O mercado brasileiro revela um cenário real de déficit de madeira, devido à produção e à grande demanda por essa matéria-prima. Uma alternativa bastante viável a fim de suprir a falta desse recurso iniciou-se com os reflorestamentos, com espécies como Pinus sp. e Eucalyptus sp. destacando-se no setor florestal brasileiro, possibilitando a produção de um material com características que podem ser manejadas adequadamente para um determinado uso. Porém, ao se pensar em reflorestamentos com espécies consideradas nobres, volta-se à falta de recurso adequado para suprir o mercado efetivamente, deixando-se de considerar que outras espécies florestais poderiam ser promissoras e tecnologicamente interessantes no abastecimento de madeira para o país. O cedro australiano (Toona ciliata) surge como 
uma opção ao uso de madeiras nobres nativas, como, por exemplo, o mogno (Swietenia macrophylla) e o cedro (Cedrela odorata). Sua madeira é descrita no meio científico como possuindo características intermediárias entre o mogno e o cedro, em termos de qualidade e utilizações.

Toona ciliata (cedro australiano) é uma espécie florestal pertencente à família Meliaceae, com grande potencial para a silvicultura comercial brasileira (ARES; FOWNES, 2000). Quanto aos aspectos inerentes à madeira, estudos apontam grande potencialidade de utilização dessa espécie de cedro na produção de produtos de maior valor agregado. A espécie apresenta um rápido crescimento e imunidade ao broqueador das pontas (Hypsipyla grandella), que afeta os cedros nativos (MANGIALAVORI et al., 2003).

O gênero Toona, segundo (BYGRAVE; BYGRAVE, 2005), destaca-se ainda pelo seu potencial produtivo, entre os gêneros pertencentes à subfamília Swietenoideae, que engloba as mais valiosas espécies de árvores das florestas tropicais, como as espécies dos gêneros Cedrela, Swietenia, Khava e Chukrasia.

A espécie foi introduzida no Brasil, onde encontrou condições edafoclimáticas favoráveis ao seu desenvolvimento. O cedro australiano apresenta bom crescimento em regiões de 500 a $1500 \mathrm{~m}$ de altitude e com regime pluviométrico de 800 a $1800 \mathrm{~mm} / \mathrm{ano}$, com dois a seis meses de estiagem, apresentando um bom desenvolvimento em plantios de regiões com $4000 \mathrm{~mm}$ de precipitação anual. Tolera geada leve de curta duração. A temperatura para o seu desenvolvimento fica em torno de 20 a $26{ }^{\circ} \mathrm{C}$, no entanto a espécie sobrevive a temperaturas mínimas absolutas pouco abaixo de $0^{\circ} \mathrm{C}$. A implantação da cultura é economicamente viável e confere um investimento rentável ao produtor, segundo análise econômica de Pinheiro et al. (2003).

A madeira apresenta densidade moderadamente leve - de acordo com trabalhos realizados por Ziech (2008), a densidade básica da madeira é de $0,306 \mathrm{~g} / \mathrm{cm}^{3}$. O cedro australiano apresenta uma ampla utilização, como, por exemplo, na construção de mobílias de luxo e embarcações, na produção de compensados, laminados, ornamentos de interior, marcenaria, instrumentos musicais, caixas e engradados, entre outros usos. Relata-se também a extração de taninos e de componentes utilizados na produção de inseticidas, essência para a indústria de perfumaria e cosméticos e medicamentos (WORLD AGROFORESTRY CENTRE, 2009).

As fibras fazem parte da constituição anatômica da madeira, tendo como função principal sua sustentação mecânica. Sendo assim, o estudo das dimensões das fibras é importante, pois se correlaciona com as propriedades físicas e mecânicas da madeira, determinando seu uso final. Madeiras que possuem fibras mais espessas possuem uma maior densidade. A morfologia das fibras varia entre espécies, entre árvores e dentro de uma mesma árvore, através das taxas de crescimento e idade das árvores, e são controladas tanto genética quanto fenotipicamente, pelas influências ambientais, geográficas ou topográficas (METCALFE; CHALK, 1989).

Segundo (BARRICHELO; BRITO, 1984; PANSHIN; ZEEUW, 1980), as fibras produzidas pela região cambial são largas, com acentuados diâmetros de lume. Como as árvores apresentam um alto ritmo de crescimento nos primeiros 10-12 anos de vida, posteriormente tendem a estagnar. As fibras mais largas e com maiores diâmetros de lume estão mais restritas à região interna do tronco, ou seja, na madeira juvenil.

No sentido axial base-topo, há um aumento de ambas as dimensões (COWN, 1975), influenciadas pelo crescimento apical e pela copa da árvore. Muñiz (1993), estudando a madeira de $P$. taeda aos 30 anos de idade, observou acréscimos na largura e diâmetro do lume das fibras até o meio do tronco. A partir dessa posição, decresceram em direção ao topo. Ambas as dimensões apresentam as mesmas tendências de variação dentro do tronco, estando fortemente correlacionadas, indicando que as fibras mais largas são também as de maior diâmetro de lume (KARTH, 1967; COWN, 1975; TOMASELLI, 1979; KIBBLEWHITE, 1980; KIBBLEWHITE, 1982; KIBBLEWHITE; LLOYD, 1983).

Com relação às microfibrilas, estas constituem as unidades fundamentais da parede celular dos elementos anatômicos das plantas. Nas camadas da parede secundária das fibras do lenho de árvores, principalmente na camada $S_{2}$, elas formam ângulos com o eixo das fibras. A inclinação das microfibrilas em relação ao eixo das fibras é importante na definição de várias propriedades da madeira, como sua instabilidade dimensional, rigidez e resistência mecânica (ZOBEL; VAN BUIJTENEN, 1989, citados por Ferreira, 2007).

Vários pesquisadores, como Wimmer et al. (2002), afirmam que a orientação fibrilar da camada $\mathrm{S}_{2}$ determina, em grande parte, as propriedades mecânicas das fibras individuais, assim como as 
propriedades da madeira sólida. Nesse caso, propriedades de resistência, de elasticidade e de retratibilidade são citadas como influenciadas pelo ângulo microfibrilar da camada $S_{2}$. Em folhosas, a orientação das microfibrilas na camada $S_{2}$ varia de $5^{\circ}$ a $20^{\circ}$ (BOYD, 1985). Apesar de pouco estudado, pode-se dizer que o ângulo das microfibrilas varia entre materiais genéticos, entre árvores e até mesmo dentro da própria árvore.

Embora se trate de uma espécie com grande potencial para a silvicultura comercial brasileira, ainda pouco se sabe sobre os aspectos tecnológicos da madeira do cedro australiano, principalmente com referência à espécie introduzida nos reflorestamentos em nosso país, em diferentes idades e locais de crescimento, tornando-se necessário seu conhecimento em relação às dimensões das fibras e ao ângulo microfibrilar. Como hipótese de trabalho, assume-se que, no sentido axial, há um aumento de ambas as dimensões, o que influencia diretamente nas características anatômicas da madeira, bem como diferentes tratos silvicultutais. Nesse contexto, o presente trabalho teve como objetivo principal contribuir para o conhecimento da espécie anteriormente citada, através dos seguintes objetivos específicos: analisar a relação da dimensão das fibras com o ângulo microfibrilar, estudar a variação axial existente nos municípios analisados e avaliar as dimensões das fibras e o ângulo microfibrilar entre os municípios.

\section{MATERIAL E MÉTODOS}

O estudo foi realizado na região sul do estado de Minas Gerais, nos municípios de Santo Antônio do Amparo (STA), Cana Verde (CV) e Campo Belo (CB). A altitude dos locais de plantio é de, respectivamente, $1020 \mathrm{~m}, 700 \mathrm{~m}$ e $945 \mathrm{~m}$. A região possui clima tropical de altitude (CWA), pela classificação de Köppen, com verões úmidos e invernos secos. Sua precipitação pluviométrica anual é de $1250 \mathrm{~mm}$, e a temperatura é em torno de $23,5^{\circ} \mathrm{C}$. O solo é do tipo Latossolo Vermelho Escuro.

Neste estudo foram utilizadas árvores de Toona ciliata com 4 anos de idade, provenientes de cada município amostrado. Em cada local foram coletadas três árvores, buscando-se selecionar indivíduos sadios e fenotipicamente representativos do plantio. A partir da altura comercial de cada árvore, foi retirada uma tábua com $5 \mathrm{~m}$ de comprimento, da qual foram retiradas amostras em três posições: base, 50 e $100 \%$, seccionadas no mesmo ponto, radialmente, ao longo da tábua, ou seja, próximo à periferia entre o cerne e o alburno, a fim de se verificar a variação no sentido base-topo (Figura 1). De cada posição, foram retirados corpos de prova de $2 \times 2 \times 2 \mathrm{~cm}$.

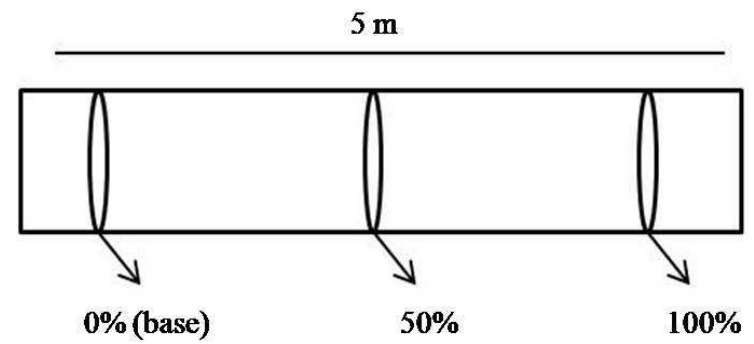

Figura 1. Esquema de corte das três posições na tábua para análise anatômica das fibras.

Figure 1. Cut outline of the three positions of the board for fiber anatomical analysis.

Os corpos de prova foram saturados na água com aplicação intermitente de vácuo e dessecador, sendo posteriormente cortados no plano tangencial no micrótomo de deslizamento em seções de $8 \mu \mathrm{m}$ de espessura. Com esses cortes, fez-se a maceração com uma solução de peróxido de hidrogênio e ácido acético glacial, na proporção de (v/v) $1: 1$, a $60{ }^{\circ} \mathrm{C}$, durante 8 horas. Em seguida, foram preparadas lâminas provisórias para a medição do ângulo microfibrilar, utilizando-se o microscópio Olympus, adaptado com polarizador de luz, com mesa giratória. Selecionaram-se 60 fibras cortadas no sentido longitudinal, para permitir que apenas uma única parede fosse atravessada pela luz. Girando-se a mesa do microscópio, colocou-se a fibra na máxima posição de extinção da luz. Nessa posição, a luz polarizada se encontra sobreposta com o mesmo alinhamento das microfibrilas, não deixando passar a luz. Girando-se manualmente a mesa giratória, obteve-se o ângulo microfibrilar formado entre a posição vertical e a nova posição do eixo da fibra. 
O mesmo material também foi utilizado e preparado para a realização das medições de comprimento das fibras, espessura de lume e parede no sentido axial do tronco das árvores nas posições base, meio e topo de cada uma das três repetições das três localidades (STA, CB e CV). Foram retirados desses corpos de prova pequenos fragmentos no formato de palitos de madeira, para a maceração. Utilizaram-se frascos de vidro de $30 \mathrm{~mL}$, nos quais foram colocadas as amostras em solução de peróxido de hidrogênio e ácido acético glacial, na proporção de 1:1(v/v). Esses frascos foram tampados e colocados na estufa, a $60{ }^{\circ} \mathrm{C}$, até a maceração completa, que ocorreu após 24 horas.

As fibras, em seguida, foram lavadas em água destilada, coradas com corante safranina hidroalcoólica $50 \%(\mathrm{p} / \mathrm{v})$ e mantidas no frasco até serem preparadas lâminas provisórias, para análise de suas dimensões.

Utilizou-se um microscópio acoplado ao sistema de análise de imagem Wincel - Pró-plus, de concepção canadense. Para as medições de comprimento de fibras, foram realizadas 30 repetições de cada árvore, em aumento de 40X. O diâmetro do lume e a largura das fibras foram medidas no aumento de 400X. A espessura da parede da fibra foi obtida pela diferença entre a largura da fibra e o diâmetro do lume, dividida por dois.

Realizou-se uma análise de correlação de Pearson com as médias de dimensões das fibras em função do ângulo microfibrilar na posição axial da madeira de Toona ciliata.

$\mathrm{O}$ experimento foi realizado seguindo um delineamento inteiramente casualizado, em esquema fatorial, constituído de 60 repetições. Os dados obtidos foram analisados no programa SISVAR, em que procedeu-se a análise de variância com nível de significância de 5\%. Posteriormente adotou-se o teste de Skott-Knott, ao mesmo nível de significância, para a comparação das médias entre os tratamentos.

\section{RESULTADOS E DISCUSSÃO}

Análise de correlação do AMF com as dimensões das fibras entre os municípios amostrados

Conforme resultados apresentados na tabela 1, verificou-se que na interação do ângulo microfibrilar com o comprimento das fibras houve correlação negativa apenas em Cana Verde (-0,76), sendo que em Santo Antônio do Amparo, mesmo sendo positiva (0,13), a correlação foi baixa, e em Campo Belo foi de 0,40. É possível que, em função da amostragem, não tendo sido possível delimitar lenho primaveril e outonal, tenha-se encontrado as correlações positivas observadas nos demais municípios. Outra possibilidade que pode justificar as diferenças observadas é o microclima de cada localidade. Para admitir essa possibilidade, faz-se necessário um estudo detalhado relacionado à atividade cambial dessa espécie em cada local amostrado. Donaldson (2008), em sua revisão sobre AMF, menciona que a literatura é controversa em relação ao tema. Alguns estudos mostraram uma relação positiva entre as dimensões das fibras e o ângulo microfibrilar, enquanto outros encontraram uma relação inversa. Evans; Ilic (2001) citam que a correlação pode ser forte em anéis muito próximos localizados no lenho adulto.

Tabela 1. Resumo da análise de correlação de Pearson do ângulo microfibrilar com as dimensões das fibras de Toona ciliata, no sentido axial, por município.

Table 1. Summary of the correlation analysis Pearson of the microfibril angle with the dimensions fibers of Toona ciliata, in the axial direction by municipal district.

\begin{tabular}{lccc}
\hline Fonte de variação & CB & STA & CV \\
\hline AMF x comprimento de fibra & 0,40 & 0,13 & $-0,76$ \\
AMF x espessura de parede & 0,92 & 0,98 & 0,40 \\
AMF x diâmetro do lume & 0,96 & 0,72 & 0,51 \\
\hline
\end{tabular}

AMF: ângulo microfibrilar; CB: Campo Belo; CV: Cana Verde; STA: Santo Antônio do Amparo.

Segundo Panshin; De Zeeuw (1980), no lenho juvenil as iniciais fusiformes são relativamente pequenas, aumentando rapidamente o comprimento até atingirem a maturidade cambial, quando as células apresentam um comprimento estável. Nesse contexto, Preston (1974) menciona que o ângulo microfibrilar apresenta a tendência geral de diminuir com o aumento do comprimento da fibra. Isso ocorre devido à baixa divisão cambial, a qual leva a um maior tempo de expansão celular, sendo que maiores ângulos são encontrados em células menores e vice-versa.

A correlação entre o AMF com a espessura da parede no município de Cana Verde foi de 0,40 e 
o diâmetro do lume 0,51 , enquanto que nos outros municípios a espessura de parede foi de 0,98 (STA) e $0,92(\mathrm{CB})$ e os diâmetros do lume foram de 0,72 para STA e 0,96 para CB, sendo que essas duas variáveis apresentaram correlações mais altas em Santo Antônio do Amparo e Campo Belo, provavelmente devido a fatores relacionados aos tratos silviculturais em cada localidade e devido às influências ambientais, como, por exemplo, no município de Cana Verde, onde a altitude é mais baixa (700 m) que nas demais localidades. As correlações positivas observadas estão diretamente relacionadas à formação da parede celular, em que, na fase de diferenciação, ocorre inicialmente a expansão celular em comprimento e posteriormente em espessura (PANSHIN; ZEEUW, 1980).

\section{Variação do ângulo microfibrilar $X$ dimensões das fibras no sentido axial}

Por meio dos resultados, pode-se observar que não houve um padrão definido de variação no ângulo microfibrilar com as dimensões das fibras no sentido base-topo, por município. Analisando o comprimento das fibras com o ângulo microfibrilar, observou-se que, nos três municípios, as fibras apresentaram-se maiores na base, seguido de uma ligeira redução no meio, com um leve acréscimo no topo (Figura 2). Já o AMF foi inversamente proporcional ao comprimento, sendo que essa relação entre as duas variáveis está de acordo com Preston (1974), o qual menciona que o ângulo microfibrilar é altamente influenciado pelo tamanho da célula. Evans (2000), estudando a variação axial em espécies de Eucaliptus, encontrou resultados semelhantes, tanto na variação base-topo quanto na correlação AMF e comprimento de fibra.
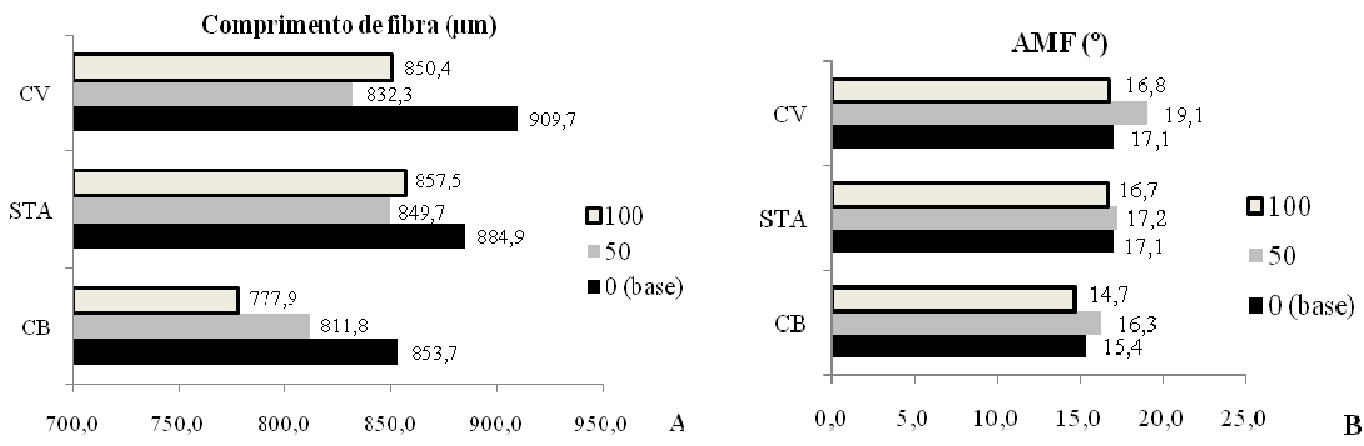

Figura 2. (A) Variação axial do comprimento das fibras; (B) AMF, Ângulo microfibrilar de Toona ciliata, por município.

Figure 2. (A) Axial variation of the fiber length; (B) AMF, microfibril angle of Toona Ciliata, by municipal district.

Comparando a espessura da parede com o AMF no sentido base-topo (Figura 3A), pode-se observar que no município de Campo Belo o espessamento da parede ocorreu de forma crescente. Quanto ao diâmetro do lume, este apresentou uma variação crescente até $50 \%$, decrescendo a $100 \%$, sendo que o AMF apresentou uma correlação inversa a $50 \%$ e $100 \%$. Quanto ao diâmetro do lume com o AMF, essa correlação foi semelhante, pois na base o AMF foi menor, aumentando discretamente a $50 \%$ e decrescendo a $100 \%$.

Para o município de Santo Antônio do Amparo (Figura 3B), a espessura da parede manteve-se constante da base até 50\%, aumentando no topo. Quanto ao diâmetro do lume, houve um ligeiro acréscimo de $0-50 \%$, decrescendo a $100 \%$. A correlação da parede com o AFM, foi relativamente inversa. Quanto ao lume, essa variação foi mínima.

Em Cana Verde (Figura 3C), o espessamento da parede manteve-se com os mesmos valores de 0-50\%, decrescendo a $100 \%$. Quanto ao diâmetro do lume, houve um acréscimo até $50 \%$, diminuindo a $100 \%$, sendo que a variável AMF apresentou o mesmo comportamento da parede e do lume.

\section{Análise estatística das dimensões das fibras e ângulo microfibrilar por localidade}

As dimensões das fibras e o ângulo microfibrilar variaram de maneira diferente em relação às 
posições base-topo das árvores nas três localidades estudadas. Os resultados expressos na tabela 2 mostram um comportamento semelhante em relação ao comprimento das fibras nas posições "base" e "topo" nas três localidades. Nos municípios de Santo Antônio do Amparo e Cana Verde diferiram apenas a 50\%. Observou-se que, para as plantas cultivadas em Campo Belo, não houve diferença estatística entre as posições axiais analisadas. O maior valor de comprimento das fibras foi encontrado no município de Cana Verde na base. Segundo Zobel; Buijtenen (1989), as mudanças no comprimento das fibras variam entre espécies, no entanto o mais comum é observar fibras mais longas na base das árvores, variação essa que pode ser explicada pelo aumento na proporção de lenho juvenil no sentido do topo. Para E. dunnii foi observado decréscimo no comprimento das fibras em direção ao topo, portanto, se o objetivo é obter fibras mais longas, a altura mais indicada para encontrá-las é de $50 \%$.
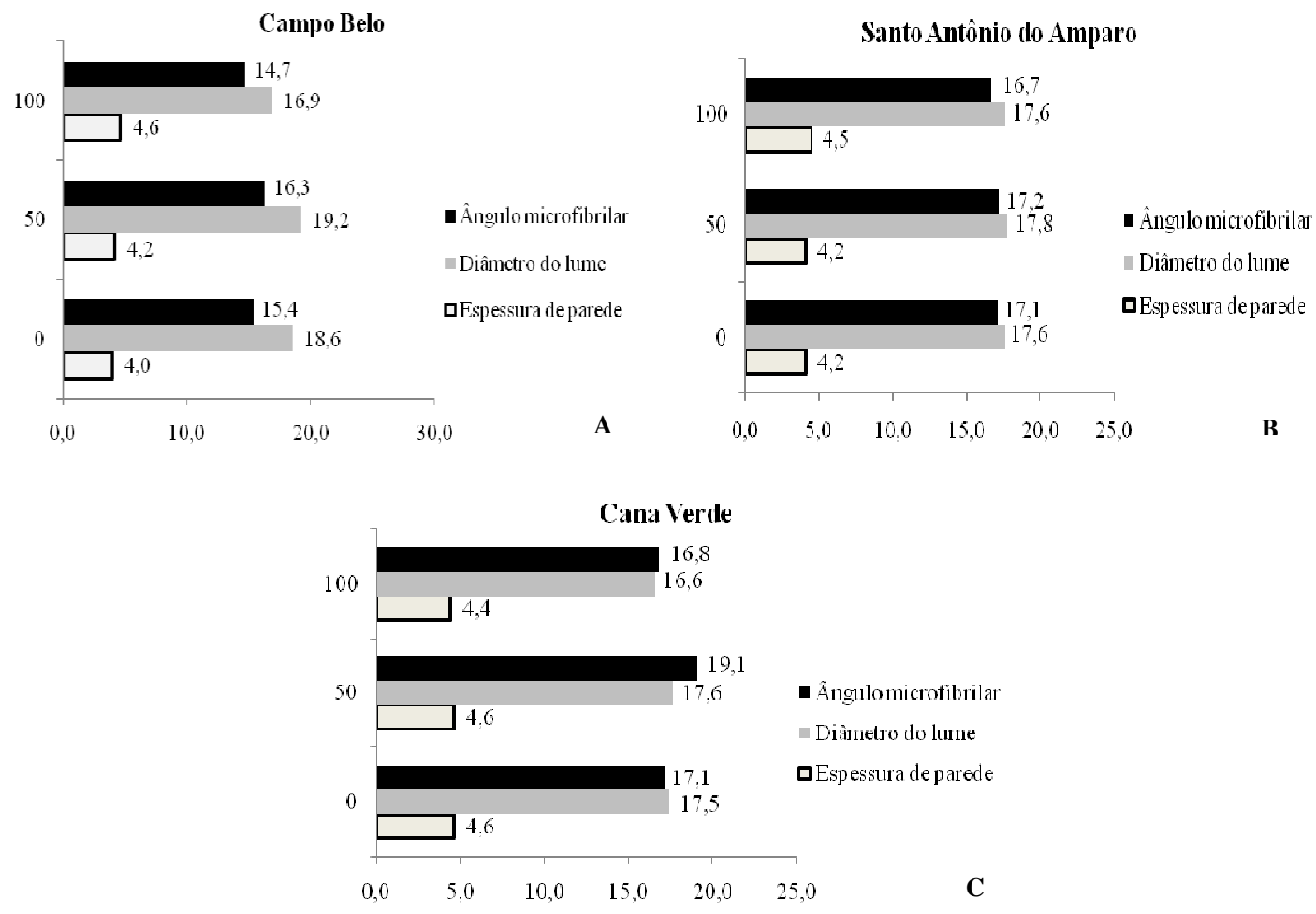

Figura 3. Variação axial da espessura de parede e diâmetro do lume com o ângulo microfibrilar de Toona ciliata, por município. (A) Campo Belo; (B) Santo Antônio do Amparo; e (C) Cana Verde.

Figure 3. Axial variation of the wall thickness and lumen diameter with the the microfibril angle of Toona ciliata by municipal district. (A) Campo Belo; (B) Santo Antônio do Amparo; e (C) Cana Verde.

Para E. grandis, Taylor (1973) detectou pequena variabilidade no comprimento das fibras na altura central das árvores. Bhat et al. (1990) avaliaram o comprimento das fibras a 0, 50 e $100 \%$ em árvores com três, cinco, sete e nove anos. Segundo esses autores, o comprimento das fibras aumentou conforme a idade. Quanto à variação em altura do tronco, houve um pequeno aumento do comprimento das fibras a $50 \%$ da altura, que decresceu, posteriormente, até o topo das árvores.

Em relação à espessura da parede das fibras, as plantas cultivadas no município de Campo Belo não diferiram entre as posições base-topo. Em Cana Verde apresentaram uma média maior em relação à base e a $50 \%$, sendo que essa variável foi estatisticamente diferente. Os valores encontrados a $50 \%$ não diferiram significativamente entre as três localidades. No município de Santo Antônio do Amparo, a parede a $100 \%$ foi mais espessa, diferindo das demais posições. As três localidades apresentaram fibras com paredes delgadas a espessas. Florsheim et al. (2009), estudando a variação nas dimensões dos 
elementos anatômicos da madeira de Eucalyptus dunnii com 7 anos de idade, encontrou valores próximos aos obtidos neste trabalho, variando de 3,95 a $4,33 \mu \mathrm{m}$.

Tabela 2. Resultados do teste de Scott-Knott, com nível de significância de 5\%, para o desdobramento do local dentro da posição para as variáveis comprimento de fibra, espessura de parede, diâmetro do lume e ângulo microfibrilar.

Table 2. Results of the Scott-Knott test, with significance level of 5\%, for the deployment of the local within the position for the variables fiber length, wall thickness, lumen diameter and the microfibril angle.

\begin{tabular}{|c|c|c|c|}
\hline Posição & CB & STA & CV \\
\hline \multicolumn{4}{|c|}{ Comprimento da fibra $(\mu \mathrm{m})$} \\
\hline $0 \%$ (base) & $853,68 \mathrm{a}$ & $884,92 \mathrm{~b}$ & $909,65 \mathrm{~b}$ \\
\hline $50 \%$ & $811,77 \mathrm{a}$ & $849,65 \mathrm{a}$ & $832,31 \mathrm{a}$ \\
\hline $100 \%$ & $777,87 \mathrm{a}$ & $857,49 \mathrm{~b}$ & $850,44 \mathrm{~b}$ \\
\hline \multicolumn{4}{|c|}{ Espessura da parede $(\mu \mathrm{m})$} \\
\hline $0 \%$ (base) & $4,04 \mathrm{a}$ & $4,15 \mathrm{a}$ & $4,60 \mathrm{~b}$ \\
\hline $50 \%$ & 4,43 a & $4,15 \mathrm{a}$ & $4,60 \mathrm{a}$ \\
\hline $100 \%$ & $4,01 \mathrm{a}$ & $4,52 \mathrm{~b}$ & $4,44 \mathrm{~b}$ \\
\hline \multicolumn{4}{|c|}{ Diâmetro do lume $(\mu \mathrm{m})$} \\
\hline $0 \%$ (base) & $18,56 \mathrm{a}$ & $17,62 \mathrm{~b}$ & $17,47 \mathrm{~b}$ \\
\hline $50 \%$ & $19,23 \mathrm{a}$ & $17,79 \mathrm{~b}$ & $17,61 \mathrm{~b}$ \\
\hline $100 \%$ & $16,91 \mathrm{a}$ & $17,60 \mathrm{a}$ & $16,55 \mathrm{a}$ \\
\hline \multicolumn{4}{|c|}{ Ângulo microfibrilar (graus) } \\
\hline $0 \%$ (base) & $15,40 \mathrm{a}$ & $17,10 \mathrm{~b}$ & $16,80 \mathrm{~b}$ \\
\hline $50 \%$ & $16,26 \mathrm{a}$ & $17,20 \mathrm{~b}$ & $19,07 \mathrm{c}$ \\
\hline $100 \%$ & $14,69 \mathrm{a}$ & $16,68 \mathrm{~b}$ & $17,07 \mathrm{~b}$ \\
\hline
\end{tabular}

CB: Campo Belo; CV: Cana Verde; STA: Santo Antônio do Amparo. Médias seguidas de uma mesma letra na linha não diferem entre si pelo teste de Scott-Knott ao nível de significância de 5\%.

Quanto ao diâmetro do lume, os valores encontrados em Campo Belo foram superiores na base e a 50\% e não diferem no sentido axial. Em relação a Cana Verde e Santo Antônio do Amparo, entretanto, a $100 \%$ diferem estatisticamente da base e a $50 \%$. Florsheim et al. (2000) observaram que no sentido base-topo o lume e a parede não mostraram variação consistente.

Urbinati et al. (2003), estudando Terminalia ivorensis, observaram aumento no comprimento das fibras no sentido do topo, enquanto o lume e a espessura da parede das células não apresentaram diferenças. Os autores sugerem que variações encontradas no sentido axial podem ser interpretadas como reflexo das diferentes idades do câmbio ao longo da altura do tronco. Quilhó et al. (2006) encontraram pouca variação nas dimensões das fibras no sentido axial em híbridos de E. grandis com E. urophylla. Resultados similares foram relatados por Wilkes (1988) ao estudar a variação anatômica em espécies de eucalipto, para as quais a variação no sentido axial foi menor do que a radial.

Zobel; Bujtenen (1989) afirmaram que as características morfológicas das fibras variam significativamente entre e dentro das árvores e podem ser controladas geneticamente, bem como apresentar alterações em função de diferentes práticas silviculturais. É possível que a variação observada nas dimensões das fibras de forma diferente nas localidades no sentido axial esteja relacionada ao tipo de preparo do solo nos locais de plantio. Apesar de não terem sido obtidas informações a respeito da composição química do solo, os locais de plantio possuem diferentes tratos silviculturais.

Verificou-se que, tecnologicamente, as árvores analisadas no município de Cana Verde apresentaram resultados mais satisfatórios em relação às dimensões das fibras, por esta apresentar maior comprimento, paredes mais espessas e lumes menores, em comparação com outras espécies de reflorestamento, como o eucalipto. Carvalho (2000), estudando E. grandis $x$ urophylla com sete anos de idade, relatou valores médios de comprimento de fibra de $1.007 \mu \mathrm{m}$ e espessura de parede de $4,49 \mu \mathrm{m}$. No entanto o cedro australiano apresenta características tecnológicas relevantes, quando comparado com eucalipto, pois apresenta crescimento rápido, podendo ser utilizado também como fonte de matéria-prima 
no setor florestal. Segundo Malan (1995), a espessura da parede das fibras está intimamente relacionada com a densidade da madeira, pois fibras das madeiras de alta densidade com paredes espessas têm baixa flexibilidade e são mais resistentes, desempenhando um papel crucial na qualidade da madeira.

De acordo com o IAWA Committee (1989), pela análise do macerado, anatomicamente as fibras do cedro australiano são classificadas como muito curtas, do tipo libriforme, com pontoações diminutas, raras fibras septadas e presença de fibras bifurcadas.

Quanto à análise do ângulo microfibrilar, observou-se que, dependendo da localidade na qual o cedro australiano foi cultivado, ocorreu a variação do ângulo com a posição no tronco. Os valores médios obtidos em relação ao ângulo nas posições base e $100 \%$ no tronco das árvores exprimem um comportamento semelhante, sendo que em Campo Belo os valores são menores, quando comparados com os das árvores de Santo Antônio do Amparo e Cana Verde. A 50\%, apenas o município de Cana Verde difere estatisticamente das demais posições, apresentando maior ângulo.

Em relação aos resultados das análises realizadas nas posições base-topo das árvores, estes diferem daqueles encontrado na literatura, pois o ângulo microfibrilar das três localidades aumentou no sentido axial, na direção base-topo. Esse fato pode ser explicado pelas influências silviculturais e ambientais que podem ter ocorrido. Segundo Marcati (1992), numerosos fatores, tanto internos quanto externos à árvore, conduzem a variações quanto ao tipo, número, tamanho, forma, estrutura física e composição química dos elementos celulares.

Conforme Boyd (1985), nas espécies de folhosas, como, por exemplo, nas do gênero Eucalyptus, a variação do ângulo microfibrilar é de $5^{\circ}$ a $20^{\circ}$, médias que condizem com os resultados deste experimento. Embora os valores obtidos por Lima et al. (2004), estudando a variação do ângulo microfibrilar das madeiras de 11 clones de Eucalyptus com 8 anos de idade, em quatro locais diferentes, tenham sido inferiores aos do cedro australiano, apresentaram valores que variaram de 7,4 a 10,0 graus e uma média de 8,8 graus.

\section{CONCLUSÕES}

Os resultados obtidos permitem concluir que:

- As dimensões das fibras e o ângulo microfibrilar do cedro australiano foram diferentes no sentido axial (base-topo) das árvores e entre os diferentes locais de crescimento analisados.

- Análise de correlação do AMF com a parede e lume das fibras foi positiva entre os municípios amostrados, sendo negativa apenas a interação AMF com o comprimento das fibras em Cana Verde. Em Santo Antônio do Amparo foi baixa.

- Não houve um padrão definido de variação no ângulo microfibrilar com as dimensões das fibras no sentido base-topo, por município.

- $\mathrm{Na}$ avaliação axial (base-topo das árvores), observou-se que na base as fibras são mais longas em ambos os municípios. Em Cana Verde, as fibras foram maiores na base, e a parede apresentou um espessamento maior na base e a 50\%. O diâmetro do lume foi inversamente proporcional. O AMF foi maior a 50\% nas três localidades, destacando-se das demais as amostras provenientes de Cana Verde. Tanto as dimensões das fibras quanto o ângulo microfibrilar se destacaram quantitativamente, devido à pouca idade das árvores, em comparação com espécies de eucaliptos citadas neste trabalho.

- Devido à pouca idade das árvores utilizadas, elas apresentam proporção alta de lenho juvenil. Dessa forma, é conveniente que este estudo seja repetido com árvores mais adultas, oriundas dos mesmos locais do experimento, de forma que se possa avaliar o efeito das diferentes intensidades da idade na madeira formada, nos anos subsequentes ao período analisado, para um melhor direcionamento do uso da espécie.

\section{REFERÊNCIAS}

ARES, A.; FOWNES, J. H. Productivity, nutrient and water-use efficiency of Eucalyptus saligna and Toona ciliata in Hawaii. Forest Ecology and Management, 139: 227-236, 2000. 
BARRICHELO, L. E. G.; BRITO, J. O. Variabilidade longitudinal e radial da madeira de Eucalyptus grandis. In: CONGRESSO ANUAL DE CELULOSE E PAPEL, 17, São Paulo, 1984. $\mathbf{1 7}^{\circ}$ Congresso... São Paulo, Associação Técnica Brasileira de Celulose e Papel, 1984. p. 403-9.

BHAT, K. M.; BHAT, K. V.; DHAMODARAN, T. K. Wood density and fibre length of Eucalyptus grandis grown in Kerala, India. Wood and Fiber Science, Kansas, v. 22, n. 1, p. 54-61, 1990.

BOYD, J. D. Biophysical control of microfibril orientation in plant cell walls. Aquatic and terrestrial plants including trees. Dordrecht, The Netherlands: Martinus Nijhoff/Dr W. Junk, 1985. 200 p.

BYGRAVE, F. L.; BYGRAVE, P. L. Growing australian red cedar and other Meliaceae species in plantation. School of Biochemistry and Molecular Biology Faculty of Science Australian National University and Rural Industries Research and Development Corporation, Canberra, 2005. 60 p.

CARVALHO, A. M. Valorização da madeira do híbrido Eucalyptus grandis x urophylla através da produção conjunta de madeira serrada em pequenas dimensões, celulose e lenha. Piracicaba, 2000. 128 p. Dissertação (Mestrado) - Escola Superior de Agricultura "Luiz de Queiroz". Universidade de São Paulo.

COWN, D. J. Variation in tracheid dimensions in the stem of a 26-year-old radiata pine tree. Appita, Carlton, v. 28, n. 4, p. 237-245, 1975.

DONALDSON, L. Microfibril angle: measurement, variation and relationship - a review. IAWA Journal 29(04): 387-396, 2008.

EVANS, R.; ILIC, J. Rapid prediction of wood stiffness from microfibril angle and density. For. Prod. J. 51(3): 53-57, 2001.

EVANS, R.; STRINGER, S.; KIBBLEWHITE, E. Variation of microfibril angle, density and fiber orientation in twenty-nine Eucaliptus nitens trees. Appita, Carlton, v. 53, n. 5, p. 450-457, 2000.

FERREIRA, S. Lenho de tração em Eucalyptus spp. cultivado em diferentes topografias. Tese (Doutorado em Ciência e Tecnologia da Madeira) - Universidade Federal de Lavras, Lavras, MG, 2007, 169 p.

FLORSHEIM, S. M. B.; COUTO, H. T. Z.; LIMA, I. L.; LONGUI, E. L. Variação da estrutura anatômica da madeira de Eucalyptus saligna aos 7 anos. Rev. Inst. Flor., São Paulo, v. 12, n. 2, p. 179-191, 2000.

FLORSHEIM, S. M. B.; COUTO, H. T. Z.; LIMA, I. L.; LONGUI, E. L. Variação nas dimensões dos elementos anatômicos da madeira de Eucalyptus dunnii aos sete anos de idade. Rev. Inst. Flor., São Paulo, v. 21, n. 1, p. 79-91, 2009.

IAWA Committee - International Association of Wood Anatomists. List of microscopic features for hardwood identification. IAWA Bulletin 10(3): 210-232, 1989.

KARTH, S. W. Factors affecting wood quality and quantity and consequently pulp manufacture. Southern Africa Forest Journal, Pretoria, v. 63, p. 17-24, 1967.

KIBBLEWHITE, R. P. Radiata pine corewood and slabwood, and their interrelations with pulp and handsheet properties. New Zealand Journal of Forestry Science, Rotorua, v. 10, n. 3, p. 533-550, set. 1980.

KIBBLEWHITE, R. P. The qualities of radiata pine papermaking fibres. Appita, Carlton, v. 35, n. 4, p. 289-298, 1982.

KIBBEWHITE, R. P.; LLOYD, J. A. Interrelations between the wood, fibre and kraft pulp properties of new-crop radiata pine corewood and slabwood. FRI Bulletin, Rotorua, n. 45, 1983. 26 p.

LIMA, J. T.; BREESE, M. C.; CAHALAN, C. M. Variation in microfibril angle in Eucalyptus clones. Holzforshung 16: 160-166, 2004.

MALAN, F. A. Eucalyptus improvement for lumber production. In: Seminário Internacional de utilização da madeira de eucalipto para serraria, 1995, São Paulo. Anais... São Paulo: IPEF/IPT, p. 1-19, 1995.

MANGIALAVORI, A.; MINETTI, M.; MOSCOVICH, F.; CRECHI, E. Dasometria en plantaciones comerciales de toona (Toona ciliata var. australis) em la Província de Salta. In: Jornadas Técnicas 
Forestales y Ambientales, 10, 2003, Eldorado, Misiones, Argentina. Anais... Eldorado: Facultad de Ciências Forestales, 2003.

MARCATI, C. R. Estudo da anatomia e das propriedades tecnológicas da madeira do angicovermelho (Piptadenia peregrina Benth). 1992. 94 f. Dissertação (Mestrado em Ciências Florestais) Universidade Federal de Viçosa, Viçosa, MG, 1992.

METCALFE, C. R.; CHALK, L. Anatomy of dicotiledons: wood structure and conclusion of the general introduction. 2. ed. Oxford: Claredon Press, 1989. 297 p.

MUÑIZ, G. I. B. Caracterização e desenvolvimento de modelos para estimar as propriedades e o comportamento na secagem da madeira de $\boldsymbol{P}$. elliottii Engelm e $\boldsymbol{P}$. taeda $\mathbf{L}$. Curitiba, 1993. 235 f. Tese (Doutorado em Engenharia Florestal) - Setor de Ciências Agrárias, Universidade Federal do Paraná.

PANSHIN, A. J.; ZEEUW, C. E. Textbook of wood technology. 4. ed. New York: McGraw Hill, 1980. $722 \mathrm{p}$.

PINHEIRO, A. L.; LANI, L. L.; COUTO, L. Cultura do cedro australiano para produção de madeira serrada. Viçosa: UFV, 2003. 42 p.

PRESTON, R. D. The physical biology of plant cell walls. London: Chapman \& Hall, 1974. 491 p.

QUILHÓ, T.; MIRANDA, I.; PEREIRA, H. Within-tree variation in wood fiber biometry and basic density of the urograndis eucalypt hybrid (Eucalyptus grandis $\mathrm{x}$ E. urophylla). IAWA J., Leiden, v. 27, n. 3, p. 243-254, 2006.

TAYLOR, F. W. Anatomical wood properties of South African Eucalyptus grandis. South African Forestry Journal, Pretoria, n. 84, p. 20-24, 1973.

TOMASELLI, I. Qualidade da madeira de Pinus elliottii, Pinus taeda e Araucaria angustifolia e sua correlação com as propriedades do papel. Relatório Final. Convênio FINEP, UFPR, n 18/79, Curitiba, 1979. p. 157-161.

URBINATI, C. V.; AZEVEDO, A. A.; SILVA, E. A. M. da; LISBOA, P. L. B. Variação estrutural quantitativa no lenho de Terminalia ivorensis A. Chev., Combretaceae. Acta Bot. Bras, São Paulo, v. 17, n. 3, p. 421-437, 2003.

WIMMER, R.; DOWNESS, G. M.; EVANS, R. Temporal variantion of microfibril angle in Eucaliptus nitens grown in different irrigation regimes. Tree Physiology, Victoria, v. 22, n. 7, p. 449-457, May 2002.

World Agroforestry Centre Agroforestree Database. A Tree Species Reference and Selection Guide in: <http://www.worldagroforestrycentre.org/sea/Products/AFDbases/AF/asp/BotanicSearch.asp>. Acesso em 10/01/2009.

ZIECH, R. Q. S. Características tecnológicas da madeira de cedro australiano (Toona ciliata M. Roem) produzida no sul do estado de Minas Gerais. Lavras. 2008. 91 p. Dissertação. (Mestrado em Ciência \& Tecnologia da madeira) - Departamento de Ciências Florestais, Universidade Federal de Lavras, UFLA, Lavras, MG.

ZOBEL, J. B.; BUJTENEN, J. P. Wood variation: its causes and control. New York: Springer-Verlag, $1989.363 \mathrm{p}$. 